\title{
Creation and study of partial waxy wheat lines adapted for the Middle Volga region of Russia
}

\author{
D-l.F. Askhadullin ${ }^{1 *}$, D-r.F. Askhadullin ${ }^{1}$, N.Z. Vasilova ${ }^{1}$, R.R. Vafin ${ }^{2}$ \\ ${ }^{1}$ Tatar Scientific Research Institute of Agriculture, FRC Kazan Scientific Center RAS, Kazan, Russia \\ ${ }^{2}$ All-Russian Scientific Research Institute of the Brewing, Non-Alcoholic and Wine Industry, FRC for Food Systems RAS, Moscow, Russia
}

DOI 10.18699/ICG-PlantGen2019-08

(c) Autors, 2019

*e-mail: tatnii-rape@mail.ru

\begin{abstract}
From crossing the winter wheat variety Starshina (has the non-functional allele Wx-A1b) and spring wheat line 0-192-03-5 (has the non-functional allele Wx-B1b), we obtained two promising lines of partial waxy wheat, which combines the non-functional alleles $W x-A 1 b$ and $W x-B 1 b$. These lines are K-243-13Wx-2 and K-243-13Wx-6. Evaluation of these lines was conducted in the Tatar Research Institute of Agriculture in 2017-2018. The analysis of agronomically valuable traits of the obtained lines of partial Waxy wheat indicates prospects for their use as prebreeding material for the development of spring wheat varieties with a modified composition of grain starch.
\end{abstract}

Key words: wheat; waxy; non-functional alleles; disease resistance; productivity.

\section{Introduction}

One of the main parameters characterizing the functional properties of starch is the ratio of amylose / amylopectin. Biosynthesis of amylose is blocked partially or completely, if no GBSS enzyme is synthesized, for the production of which Waxy-genes are responsible. Non-functional alleles of Waxygenes cause synthesis disorders and changes in the localization of amylose in starch. Wheat samples carrying non-functional alleles at three loci are called 'Waxy wheat', and those carrying non-functional alleles at one or two loci are called 'partially Waxy wheat'. The creation of Waxy wheat varieties makes it possible to open new directions in the use of wheat grain. The search for non-functional alleles of Waxy-genes in Russian wheat varieties showed that these mutations are extremely rare (Klimushina et al., 2012; Abdulina et al., 2013; Boboshina, Boronnikova, 2013; Netsvetaev et al., 2015). The null allele $W x-D 1 b$ was not found in Russian varieties. The aim of our research was to assess the agronomically valuable traits of our two promising lines of partially Waxy wheat combining the non-functional alleles $W x-A 1 b$ and $W x-B 1 b$.

\section{Materials and methods}

We obtained two promising lines of partial waxy wheat, which combine the non-functional alleles $W x-A 1 b$ and $W x-B 1 b$. These lines were developed from hybridization of the winter wheat variety Starshina (has the non-functional allele $W x-A 1 b$ ) and spring wheat line O-192-03-5 (has the non-functional allele $W x-B 1 b)$ and were designated as K-243-13Wx-2 and K-243-13Wx-6.

The screening of wheat lines and varieties is performed with the molecular markers specific for the alleles of the analyzed gene loci (Table 1).

Nucleic acid extraction from wheat grains of milky-wax ripeness of the 2017 generation was performed using a commercial set of 'DNA-sorb C' (Central Scientific Research Institute of Epidemiology, Russia) in accordance to the manufacturer's instructions.

Evaluation of these lines was conducted in the Tatar Research Institute of Agriculture in 2017-2018. The Tatar RIA is located in the northern part of the Middle Volga region of Russia.

Table 1

List of the primers, protocols of PCR amplification for the identification of alleles of wheat Waxy genes

\begin{tabular}{|c|c|c|}
\hline Names and sequences of oligonucleotide primers & Alleles & Amplification protocols \\
\hline 4F: 5'-AAGAGCAACTACCAGT-3' & Wx-A1 & \multirow{3}{*}{$\begin{array}{l}\times 1: 94{ }^{\circ} \mathrm{C}, 4 \mathrm{~min} . \times 40: 94{ }^{\circ} \mathrm{C}, 30 \mathrm{sec} ; 58^{\circ} \mathrm{C}, 30 \mathrm{sec} ; \\
72{ }^{\circ} \mathrm{C}, 30 \mathrm{sec} \times 1: 72{ }^{\circ} \mathrm{C}, 7 \mathrm{~min} .\end{array}$} \\
\hline 4R: 5'-TCGTACCCGTCGATGAAGTCGA-3' (Vanzetti et al., 2009; & Wx-B1 & \\
\hline McLauchlan et al., 2001) & Wx-D1 & \\
\hline 4F-c. 5'-CCCCCAAGAGCAACTACCAGT-3' & Wx-A1 & \multirow{3}{*}{$\begin{array}{l}\times 1: 94^{\circ} \mathrm{C}, 4 \mathrm{~min} \times 40: 94^{\circ} \mathrm{C}, 30 \mathrm{sec} ; 64^{\circ} \mathrm{C}, 30 \mathrm{sec} ; \\
72^{\circ} \mathrm{C} 30 \mathrm{sec} \times 1: 72^{\circ} \mathrm{C}, 7 \mathrm{~min} .\end{array}$} \\
\hline 4R-C. & Wx-B1 & \\
\hline 4R: S-ICGIACCCGICGAIGAAGICGA-3' (Vafin et al., 2015) & Wx-D1 & \\
\hline 4F-c: 5'-CCCCCAAGAGCAACTACCAGT-3' & Wx-B1 & $\times 1: 94^{\circ} \mathrm{C}, 4 \mathrm{~min} . \times 40: 94^{\circ} \mathrm{C}, 15 \mathrm{sec} ; 65^{\circ} \mathrm{C}$ \\
\hline Wx-B2R: 5'-CGTTGACGATGCCGGTGTTG-3' (Vafin et al., 2015, 2018) & (B1b) & $15 \mathrm{sec} ; 72^{\circ} \mathrm{C}, 15 \mathrm{sec} \times 1: 72^{\circ} \mathrm{C}, 7 \mathrm{~min}$ \\
\hline AFC: 5'-TCGTGTTCGTCGGCGCCGAGATGG-3' & Wx-A1 & $\times 1: 94{ }^{\circ} \mathrm{C}, 4 \mathrm{~min} . \times 40: 94^{\circ} \mathrm{C}, 30 \mathrm{sec} ; 65^{\circ} \mathrm{C}, 30 \mathrm{sec}$; \\
\hline AR2: 5'-CCGCGCTTGTAGCAGTGGAAGTACC-3' (Nakamura et al., 2002) & (A1b) & $72{ }^{\circ} \mathrm{C}, 1 \mathrm{~min} \times 1: 72^{\circ} \mathrm{C}, 7 \mathrm{~min}$. \\
\hline
\end{tabular}




\section{Results and discussion}

The average yield of line K-243-13Wx-6 was $276 \mathrm{~g} / \mathrm{m}^{2}$, which is much lower than that of the standard variety Yoldyz, $550 \mathrm{~g} / \mathrm{m}^{2}$. Line $\mathrm{K}-243-13 \mathrm{Wx}-2$ has an average yield of $534 \mathrm{~g} / \mathrm{m}^{2}$. The average weight of 1000 grains in K-243-13Wx-2 is $49.6 \mathrm{~g}$. In K-243-13Wx-2, the degree of lesion by leaf rust was $0-15 \%$, the degree of damage by stem rust was $15 \%$. This line is susceptible to powdery mildew, its resistance is 3 points ( 9 points is the maximum). Line $\mathrm{K}-243-13 \mathrm{Wx}-6$ is susceptible to leaf rust, the degree of damage was $15-50 \%$. Line K-43$13 \mathrm{Wx}-6$ is susceptible to stem rust, the degree of damage was $30-70 \%$. Resistance to powdery mildew of this line in epiphytotic 2017 was 4 points. In K-243-13Wx-2, the earing date is 1 day before that of O-192-03-5. In K-243-13Wx-6, the earing date is the same as in O-192-03-5. According to the analysis of the grain harvested in 2018, K-243-13Wx-2 and $\mathrm{K}-243-13 \mathrm{Wx}-6$ have a high protein content in the grain of 14.9 and $14.5 \%$, respectively, and have a high gluten content in the grain of 30.8 and $31.7 \%$, respectively.

\section{Conclusions}

The evaluation of agronomically valuable traits of the obtained lines of partial Waxy wheat (K-243-13Wx-2 and $\mathrm{K}-243-13 \mathrm{Wx}-6$ ) indicates prospects for their use as a starting prebreeding material for the development of spring wheat varieties with a modified composition of grain starch. In addition, the yield of line K-243-13Wx2 following two years of testing was not inferior or was higher than that of the sibs. The productivity of K-243-13Wx2 significantly exceeded the productivity of foreign varieties: Barunga, Ones 53 , Renee, Adisiba, Sonora 37, all carrying the $W x-B 1 b$ allele. Their yield was $35-51 \%$ of the yield of line K-243-13Wx2 carrying two Null-alleles. Whether line K-243-13Wx2 is suitable for industrial introduction will be shown by analysis of the the starch grain properties.

\section{References}

Abdulina I.R., Vafin R.R., Tyulkin S.V. et al. Detection of null WxB1b-allele of the Waxy-gene in spring wheat genotypes of Russian breeding. Modern Problems Science Education. 2013;2 (in Russian).

Boboshina I.V., Boronnikova S.V. Allelic variants of Waxy genes in Triticum aestivum L. cultivars grown in the Perm region and Bashkiria. Vavilov J. Gen. Breed. 2013;17(3):535-540.

Klimushina M.V., Gladkih N.I., Divashuk M.G. et al. Distribution of allelic variants of $W x$ genes in the common wheat collection made at the Krasnodar Lukyanenko research institute of agriculture. Vavilov J. Gen. Breed. 2012;16(1):187-192.

McLauchlan A., Ogbonnaya F.C., Hollingsworth B., Carter M., Gale K.R., Henry R.J., Holton T.A., Morell M.K., Rampling L.R., Sharp P.J., Shariflou M.R., Jones M.G.K., Appels R. Development of robust PCR-based DNA markers for each homeo-allele of granulebond starch synthase and their application in wheat breeding programs. Austral. J. Agricul. Res. 2001;52(11-12):1409-1416.

Nakamura T., Vrinten P., Saito M., Konda M. Rapid classification of partial waxy wheats using PCR-based markers. Genome. 2002;45: $1150-1156$.

Netsvetaev V.P., Ryzkova T.A., Tretyakov M.U. The quality of soft wheat. Belgorod, 2015. ISBN 978-5-85153-155-2 (in Russian).

Vafin R.R., Rzhanova I.V., Askhadullin D.F., Askhadullin D.F., Vasilova N.Z., Tagirov M.Sh., Tyulkin S.V., Abdulina I.R., Shagalieva G.I. Identification of Triticum aestivum L. genotype by allelic versions of waxy-genes and hmw glutenin subunits. Ecol., Envir. Conser. 2015;21:137-143.

Vafin R.R., Rzhanova I.V., Askhadullin D.F., Askhadullin D.F., Vasilova N.Z. Screening of the genotypes of bread wheat (Triticum aestivum L.) by the allelic variants of waxy genes and hmw glutenin subunits. Acta Agrobot. 2018;71(4):1746. DOI 10.5586/aa.1746

Vanzetti L.S., Pfluger L.A., Rodriguez-Quijano M., Carrill, J.M., Helguera M. Genetic variability for waxy genes in Argentinean bread wheat germplasm. Electr. J. Biotechnol. 2009;12(1):1-9.

Acknowledgements. This research was supported by FASO Russia project AAAA-A18-118031390148-1.

Conflict of interest. The authors declare no conflict of interest. 